\title{
XXIV. On electromagnetic stress
}

\section{E. Taylor Jones B.Sc.}

To cite this article: E. Taylor Jones B.Sc. (1895) XXIV. On electromagnetic stress, Philosophical Magazine Series 5, 39:238, 254-267, DOI: 10.1080/14786449508620718

To link to this article: http://dx.doi.org/10.1080/14786449508620718

$$
\text { 曲 Published online: } 08 \text { May } 2009 .
$$

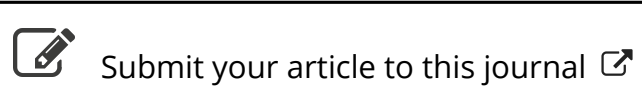

\footnotetext{
Џll Article views: 3
}

Q View related articles

4 Citing articles: 5 View citing articles 
be indicated that there is a certain value of $\mathrm{L}$ which produces the most efficient result.

If $L=0, W$ equals 0 ; if $L=\infty, W$ equals zero; so that there is some value of $L$ between 0 and $\infty$ which it is best to employ.

The actual problem, which I have not gone into, is more complicated still ; for both $\mathrm{K}$ and $\mathrm{L}$ depend on the winding: for precise treatment, a certain type of winding might be adopted, and $K$ and $L$ made to depend on some variable depending on the character of the winding; perhaps experiments would give results more readily than mathematics.

\section{ADDENDUM III.}

Each resistance of variable self-induction was made of two bobbins, one of which rotated within the other, after the manner of those described by Lord Rayleigh in Phil. Mag. 1886, xxii. p. 473.

To compare and graduate the self-inductions I used a method which was very convenient and sensitive, a modification of that described in Clerk-Maxwell, vol. ii. art. 757.

The adjoining figure represents a Wheatstone's bridge; the Jetters have their usual significance. Let self-induction of $A D=L$, of $C D=L^{\prime}$.

$\mathrm{P}, \mathrm{Q}, \mathrm{R}, \mathrm{S}$ were arranged so that with a steady current and galvanometer no current went through the galvanometer.

The galvanometer was then replaced by a telephone, the steady by an alter-

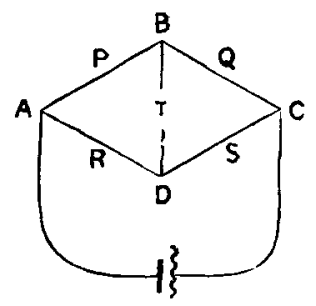
nating current, and the rotating bobbin of one of the resistances was rotated until no noise was heard in the telephone. In this case

$$
\frac{\mathrm{L}}{\mathrm{L}^{\prime}}=\frac{\mathrm{R}}{\mathrm{S}}=\frac{\mathrm{P}}{\mathrm{Q}} .
$$

XXIV. On Electromagnetic Stress. By E. TAYLOR Jones, B.Sc., Science Scholar of Royal Commission for Exhibition of 1851, nominated by the University College of $N$. Wales*.

THE problem of finding experimentally the true relation 1 between electromagnetic stress, or " lifting-power" per unit area of magnets, and magnetization has been attacked by many experimenters during the last sixty years; but no one

\footnotetext{
* Communicated by Lord Playfair, F.R.S.
} 
has succeeded in determining accurately what function of the intensity of magnetization or of the induction the stress really is. In order to show how the methods of experimenting have developed, and how they have led to those of the present investigation, I will describe shortly the chief experiments that have so far been made*.

As long ago as 1833 Fechner $\dagger$ made a series of measurements of the weight necessary to separate a horseshoe magnet and its keeper, measuring the current by swinging a magnetic needle within a coil through which the current passed. $\mathrm{He}$ found a rough proportionality between the limiting weight and the current.

Somewhat more accurate experiments made in 1839 by Lenz and Jacobi $\ddagger$ showed that this proportionality did not exist. In the same year Joule , measuring the magnetizing current with an ingenious "current-weigher," found that for small currents the lifting-power of an iron electromagnet was proportional to the square of the magnetizing current, but that for stronger currents the lifting-power increased more slowly and ultimately reached a maximum value of $140 \mathrm{lb}$. per square inch ; twelve years later $\|$, however, using a more powerful electromagnet, he found the maximum valne to be $175 \mathrm{lb}$. per square inch.

In 1852 Dub If found that the lifting-power was proportional neither to the current nor to the square of the current, but to some intermediate function, and for strong currents reached a maximum.

Much more accurate experiments were made in 1870 by v. Waltenhofen**. Two similar bars of iron with plane ends were bent approximately to semicircles and wire wound evenly on both. One bar was fixed rigidly in a frame and the other one pulled up from it, the necessary force being measured by a spring-balance. A third bar and coil, similar to the other two but straight, was set up with a compensating-coil in the East and West line through a magnetometer-needle. All these coils were in circuit with a galvanometer for indicating the current.

The stress between the bent electromagnets could thus be compared with the magnetic moment of the straight one, and

* Cf. also Wiedemann, Elek. iii. Bd. 3, pp. 632-654; du Bois, Magnetische Kreise, sect. 105-110 (1894).

+ Schweigg. Journ. lxix. (1833).

† Pogg. Ann. xlvii. p. 415 (1839).

\$ Phil. Mag. Dec. 1851.

I Pegg. Ann. Ixxxvi. p. 553 (1852).

$\|$ Ibid. Jan. 1852.

* Wien, Ber. lxi. p. 739 (1870). 
with the magnetizing current. With small currents the liftingpower increased more rapidly than the magnetometer-deflexion, but with stronger currents more slowly, the corresponding curve ultimately approaching a horizontal asymptote. Also the lifting-power was proportional neither to the current nor to its square, but was represented approximately by a function of the form $b \tan ^{-1}(a c)$, where $c$ is the current, and $a, b$ constants.

The magnetizing forces, however, used in these experiments could have been but small, since the straight magnet was never more than half saturated, and its magnetization was always nearly proportional to the current.

The next experiments were made in 1881 by Werner v. Siemens*. The electromagnets were made by cutting an iron tube in a plane through the axis, and winding both halves with wire. The interfaces were carefully ground together. A ballistic galvanometer and secondary coil were used to measure the induction. From the total induction"throw" was subtracted the throw caused by breaking the current in the coil after the iron was removed. The resulting differences are therefore proportional to the intensity of magnetizition, not to the induction.

The result showed that the lifting-power was approximately proportional to the magnetic moment per unit volume, but that the ratio somewhat increased as the current was increased. Similar resulis were obtained with electromagnets formed by cutting a circular iron tube in the plane through the greatest section.

Siemens believed the above law to be established, and attributed the deviations to residual magnetism, and to imperfect contact of magnet and keeper due to bending, the imperfect state of the surfaces, and other mechanical causes. These were the probable causes of much greater errors than those believed to exist.

In 1882 Wassmuth $†$ experimented with magnets similar to those used by v. Waltenhofen. The induction was measured ballistically, and the ends of the magnets were ground plane and polished. The magnetic moment per unit volume was calculated from the induction-current and the results compared with a theory given by Stefan $\ddagger$, according to which the stress is proportional to the square of the magnetic moment per unit volume at the surface of contact. Wassmuth

\footnotetext{
* Wied. Ann. xiv. p. 640 (1881).

$\dagger$ Wien. Ber. lxxxv. p. 327 (1882).

† Ibid. lxxxi. ii. p. $89(1880)$.
} 
found, however, that the stress agreed better with an expression of the form

$$
a+b \mathrm{I}^{2}+\frac{c \mathrm{I}^{2}}{d+c \mathrm{I}^{2}},
$$

where $I$ is the magnetic moment per unit volume. Wassmuth's experiments are subject to the same objections as Siemens', viz., imperfect contact of magnet and keeper due to bending \&c., and, in addition, to the difficulty of ensuring that the magnets separate at the two places of contact exactly simultaneously. If separation takes place at one place first, there will be an immediate diminution of the induction, and the limiting weights will generally be too small.

Wassmuth further deduced from Siemens' numbers an expression for the lifting-power of the form $a+b \mathrm{I}^{2}+c \mathrm{I}^{4}$, which represented the latter's results fairly well.

Neither Siemens nor Wassmuth appears to have thought of comparing his results with the theory given in sections 641-644 of Maxwell's 'Electricity and Magnetism,' which had been published several years before. Maxwell there arrives at the expression $\mathrm{B}^{2} \mathrm{~A} / 8 \pi$ for the electromagnetic traction in air between two opposing, plane, infinitely near, and uniformly and normally magnetized pole-faces each of area $\mathrm{A}$; where $\mathrm{B}$ is the induction.

In 1886 Bosanquet* experimented with two straight iron electromagnets whose ends were ground together. One electromagnet was fixed vertically, and the other supported beneath it on the beam of a balance by which its weight was compensated, this allowing measurements with very small currents to be made. Weights were placed in a scale-pan suspended from the lower electromagnet, and the induction was measured by a small secondary coil near the surface of contact.

For low and medium currents the weights supported were much greater than those given by Maxwell's theory, the values being better represented by an expression of the form $a \mathrm{~B}+b \mathrm{~B}^{2}$; while with high currents the results appear to be very uncertain, most of the readings widely differing from the theoretical values. The mean results, however, agree to within about 5 per cent.

In the same year Bidwell $\dagger$ made a series of measurements of the tractive force between two bar-magnets, and of the magnetizing current, but not of the induction, his object

* Phil. Mag. xxii. p. 535 (1886).

$†$ Proc. Roy. Soc. xl. p. 486 (1886). 
being to measure the induction from the values of the tractive force, using Maxwell's expression.

Quite recently an important paper has been published by Threlfall*, giving an account of experiments made with apparatus essentially similar to Bosanquet's ; but the interfaces of the electromagnets were carefully ground and polished, and the tractive force was measured by a spring-balance.

The results for high inductions do not show better agreement than Bosanquet's with Maxwell's theory ; but the author explains an important source of error which exists especially in working at low inductions, viz.- that the interfaces of the magnets do not generally remain in contact until the stress is completely overcome, but separate at one side first, thus enclosing a "wedge-shaped gap." The numbers given, however, only extend over a range of inductions from 11,000 to 16,000 C.G.S. units. Most of the paper deals with the case when the bars are separated by layers of nonmagnetic substance.

It was clear, therefore, that more accurate experiments were necessary to determine whether Maxwell's expression represents exactly the tractive force, and if so, how apparatus is to be arranged so as to allow of the accurate measurement of induction by tractive experiments.

\section{Present Experiments. Apparatus.}

The following experiments were begun in October 1893 . The apparatus was devised with a view to realizing as closely as possible the conditions under which the results could best be compared with Maxwell's theory, and was prepared and arranged as follows :-

A chosen bar of soft German iron was turned accurately to an ellipsoid of revolution of length 22.57 centim. and least diameter 1.5 centim. Its shape was tested by measuring its volume by weighing in air and water, and by calculating the volume from the above values of the axes. The two values agreed to within a tenth per cent. The ellipsoid was afterwards cut through in the equatorial plane, the diminution of length being measured by observing the distance between two marks on its surface.

Two exactly similar magnetizing-coils were made, each 20 centim. long., and having 12 layers of 70 turns each of 2 millim. aluminium wiret.

* Phil. Mag. July 1894.

$\dagger$ Aluminium wire was used that the coils might be as light as possible, it being thought desirable not to use the compensating arrangement adopted by Bosanquet, as this probably introduced errors due to friction. 
The two halves of the ellipsoid were soldered into tubes which could be fitted tightly, axially, into the coils, the free ends projecting by amounts regulated by nuts, $\mathrm{N}$ (fig. 1),

Fig. 1.-Longitudinal vertical section of Traction Apparatus.

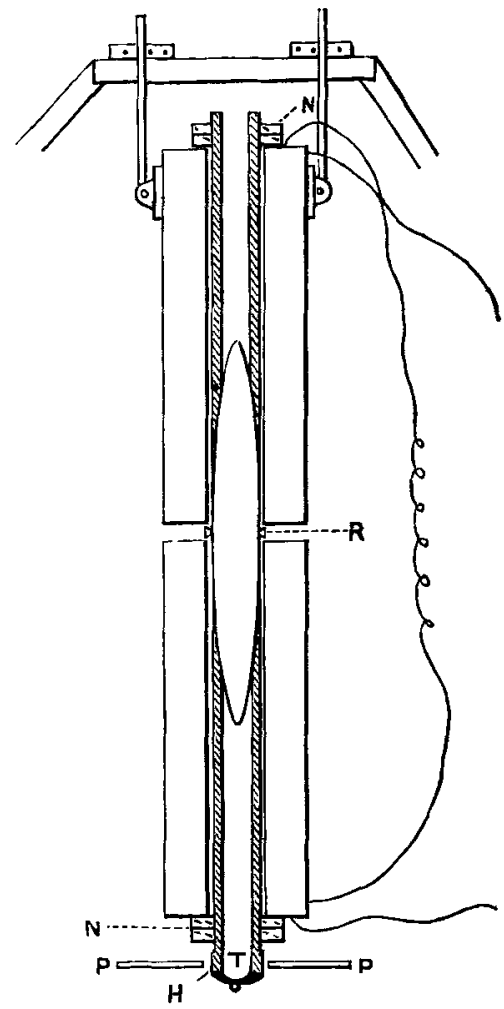

running on the tubes. To secure good alignment of the halfellipsoids, a small brass ring, $\mathrm{R}$, of 1 millim. width, was made to fit tightly on one half and loosely on the other at the plane of contact. This ring was afterwards found to be an important part of the apparatus, results obtained withont it being very uncertain.

To the absence of such a guide in Bosanquet's experiments may probably be attributed, to some extent, the uncertainty of his results, especially at high inductions.

One coil was suspended from a tripod stand by two rods provided with nuts and screws, by which and two other screws (not shown in the diagram) the coil could be raised or lowered, levelled, and rigidly fixed. Below this was a platform, $\mathrm{P}$, with 
an opening through which passed the lower projecting end of the tube in the other coil, and to this was attached a hook and scale-pan.

The current, obtained from a battery of accumulators, was measured by a Siemens and Halske's torsion-galvanometer, standardized by electrolysis.

The magnetization was measured in independent experiments by the magnetometer method.

The ellipsoid and coils were placed in the magnetic east and west line east of a delicate magnetometer read by telescope and scale.

'The intensity of the earth's horizontal field was measured by the method of Gauss and by the tangent-galvanometer method, a Koblrausch's local-variometer being found useful for measuring its variations.

The magnetization-curve was first obtained, showing the relation between $\mathrm{I}$ and $\mathrm{H}$, allowance being made, as usual, for the demagnetizing-force of the ellipsoid calculated from the expression given in Maxwell's 'Electricity and Magnetism' (Sect. 438). The intensity of magnetization I was calculated in absolute units from the formula*

$$
h \tan \theta=\frac{2 v \mathrm{I}}{d^{3}}\left\{1+\frac{6}{5} \frac{e^{2}}{n^{2}}+\frac{9}{7} \frac{e^{4}}{n^{4}}+\frac{4}{3} \frac{e^{6}}{n^{6}}+\ldots\right\},
$$

where $h=$ earth's horizontal field, $\theta=$ deflexion of needle, $v=$ volume and $e=$ eccentricity of ellipsoid, $d=$ distance of needle from centre of ellipsoid (the former being in the prolongation of the axis of the latter), and $n=\frac{d}{c}, c$ being the
semiaxis of the ellipsoid.

This curve being determined once for all, the induction $\mathrm{B}$ corresponding to any current could be calculated, since $\mathrm{B}=\mathrm{H}+4 \pi \mathrm{I} \uparrow$. All precautions were taken to determine the curve as accurately as possible, the torsion of the magnetometer-fibre, the exact position of the needle with respect to the axis of the ellipsoid, the length of a division on the scale, the effect of the compensating-coil at all parts of the scale (by deflecting with permanent magnets), and the temperature of the room during the local-variometer experiments all being carefully examined. The residual magnetism was very small, being less than a sixtieth of the total magnetization when the ellipsoid was strongly magnetized. Each current was

* This was obtained from Thomson and Tait's expression for the potential at an external point due to an ellipsoid of attracting matter by differentiating twice with respect to the distance of the point. ( $C F$. Roessler, Dissertation, Zürich, 1892).

$\dagger$ Where $\mathbf{H}=$ Field due to coils - demagnetizing force of ellipsoid. 
reversed, and half the double deflexion of the needle taken as the deflexion corresponding to the mean of the two currents, which were generally the same*

The "lifting" experiments were then proceeded with :-

The upper coil was first suspended vertically and symmetrically above the opening $H$, in the platform $\mathrm{P}$ (fig. 1 ), the lower bar and coil being thus supported (when the current was made) so that its tube $\mathrm{T}$ passed freely through the opening $\mathrm{H}$.

Enough weights were placed in the scale-pan to nearly overcome the stress, the remainder being slowly poured in in the form of fine shot until the lower coil fell. The current was then read off and the shot weighed.

This was repeated for a number of currents ranging from 1 to 10 amperes (the corresponding inductions ranging from 6000 to 20,000 C.G.S.); the adjustment of the upper coil being made before every reading, and the surfaces carefully cleaned with a soft dry brush.

The " reversed" readings were also taken, as in the magnetometer experiments.

The inductions corresponding to the currents used were calculated from the magnetization-curve. The inductions and the square roots of the observed weights were plotted in a diagram along with the straight line representing Maxwell's law.

\section{First Experiments.}

The first experiments were made with the contact-surfaces of the ellipsoid turned truly plane but not polished.

The curve representing the observed results was at low inductions considerably above the straight line (the observed weights being greater than those given by Maxwell's law), soon crossing it and remaining below it for high inductions, the difference increasing with the induction.

The correction due to the excess of area of the coils over that of the core was found by removing the cores and supporting the lower coil in the same position on a balance.

* (1) It may be objected that the magnetization in the "lifting" experiments was not the same as in the magnetometric experiments, on account of the longitudinal pull existing in the former; but a small calculation shows that, with the weights used, this effect was in general very small, and could, except perhaps at the highest inductions, be neglected.

(2) The magnetization-curve was determined both before and after the ellipsoid was cut, and the demagnetizing-force (which was affected by the shortening of the ellipsoid after the cutting) calculated in both cases. The curve for the cut ellipsoid was lower than the other; but the difference was very slight, especjally at high fields.

Phil. Mag. S. 5. Vol. 39. No. 238. Mareh 1895. T 
The current was made, and weights added until the coil returned to its original position. These added weights measured the total attraction of the coils. From this must be subtracted the part corresponding to the area occupied by the core, since this is already included in B.

The correction was found to be negligible, never being more than a sixth per cent. of the attraction of the electromagnets, and for small currents less than a twentieth per cent.

Another correction is due to the effect of the surfacedistribution of magnetism on the ellipsoid in so far as the corresponding tubes of force pass through the air. This correction, which vanishes with ring-magnets and infinitely long cylinders, was found on calculation to amount to less than $\frac{1}{10}$ per cent.

The interfaces of the ellipsoid were then polished by the firm Hartmann and Braun of Frankfurt. In this process the surfaces were surrounded with wide "guard-rings" to keep the edges as sharp as possible. The mirrors showed a so-called "black polish," and gave a perfectly clear image with a 32-magnifying-power telescope and scale at a distance of 5 metres. It would be hardly possible to obtain on metal a nearer approach to an absolutely geometrical plane.

Also in order better to guide the lower coil, the opening in the platform $P$ (fig. 1) was made smaller, just large enough, in fact, to allow the tube to pass freely through it. A series of readings was taken, as before, and these agreed considerably better with Maxwell's theory both for low and for high, but especially for low inductions.

This I attributed chiefly to the improved guiding of the lower coil; and it was found that at low inductions, by very slightly altering the position of the upper coil, a position could be found in which the tractive force was a minimum, and that if the applied weights were rather less than this minimum value the upper coil (never being absolutely rigidly fixed), on being slowly moved towards the "minimum" position, suddenly jumped across it, thus showing, so to speak, a preference for positions in which it could support heavier weights or the actual weight more easily.

The measurements were therefore made as follows:-The current being kept constant, shot was poured into the scalepan in small instalments, the upper coil after each addition being carefully moved by hand until the " minimum "position (easily observed by the jerk) was found. This was repeated until the coil fell in this position.

The explanation of this is given in Threlfall's paper ( $l . c$.$) ,$ in which it is shown that at small ind nctions the tractive force is less when the two pole-faces are everywhere in contact 
than when they are separated at one side, thus enclosing a wedge-shaped gap.

This was the case in the present experiments up to inductions of about 14,000 C.G.S.

For bigher inductions the tractive force is greatest when the surfaces are everywhere in contact, the upper core and coil therefore assuming naturally the proper position, provided, of course, the screw-adjustment is first sufficiently good. For inductions up to about 14,000 C.G.S., therefore, the lower bar was in unstable equilibrium when in good contact with the upper, for higher inductions in stable equilibrium; at about 14,000 the equilibrium was indifferent, and the nature of the contact was found within wide limits to have no influence on the Tractive Force.

As regards the results showing better agreement with the theory than before at higher inductions, I attribute this to a better method of testing the screw-adjustment of the upper coil, and partly, perhaps, to the improved state of the contactsurfaces after polishing.

At this stage the weights were all smaller than those calculated from Maxwell's expression, but their square roots were approximately proportional to the induction for inductions up to about 14,000 units, being still smaller at higher inductions, the deviation from the theoretical values increasing to about 3 per cent. at $B=20,000$.

The uniformity of these results led me to believe that the errors, if any existed, were not accidental but due to some cause which acted always in the same way. Accordingly, I tried the effect of increasing the distance between the coils, thus leaving a greater part of the core near the plane of contact unsurrounded with coil-windings. I found that the effect of increasing this distance by about 2 millim. was very slight for inductions up to about 14,000 C.G.S., and for higher inductions was a diminution of Tractive Force of a few hundred grammes, varying with the induction-differences of the same order as the differences between the above observed and calculated values. I could also increase the Tractive Force by an amount of the same order by putting between the coils a few extra turns of wire. As the actual distance between the windings of the two coils (including the end-plates and the space occupied by the small guiding ring) in the above experiments was about 5 millim., it was clear that the observed weights were on this account smaller than the theoretical values; in other words, that the induction, as calculated from the magnetization-curve, was greater than the actual induction across the surface of contact.

This result can be easily explained; for when the induction T 2 
is low the permeability of iron is great, and the tubes of induction pass more readily throngh the iron; but when the induction is high and the permeability small the absence of coil-windings near the surface of contact causes a greater proportion of tubes to pass out into the air; in other words, causes a greater spreading of the tubes. The effect of the absence of a given number of turnings near the plane of section might be calculated [see Neumann : "Ueber die Magnetisirung eines Drehungsellipsoids," Crelle, Bd. xxxvii. (1848)], but it was deemed better first to diminish the gap between the coils as much as possible. With this object the coils were somewhat altered, the end-plates being altogether removed and the small guiding ring being let into one of the coils. The gap-width could then be reduced to zero, but a width of about 1.5 millim. was necessary in order to examine the contact of the pole-faces. The effect of this was to increave the Tractive Force by several hundred grammes at all inductions, the increase being greatest at high inductions. The magnetization-curve was carefully re-determined and the results calculated out as before. The attraction of the coils alone was also remeasured, but found not to have been appreciably increased by the shortening of the gap.

\section{Final Results.}

The results now agreed with Maxwell's theory to one-half per cent. for inductions up to 19,000 units, but between 19,000 and 20,000 units the square roots of the observed weights are rather more than 1 per cent. below the calculated values.

This difference at high inductions might well be due to the fact that there was still a gap of 1.5 millim. between the coils, which would have a spreading effect at high inductions; to the effect of the stress on the magnetization ; or to temperature effects, the coils being considerably heated by a current of 10 amperes. A better agreement with the theory was therefore hardly to be expected.

No readings could be taken at inductions below 6000 , since the weight of the lower coil and half-core was sufficient to overcume the stress at this induction. The following table gives the values of the intensity of magnetization, induction, and the square roots of the theoretical and observed Tractive Forces measured in grammes weight; and the diagram (fig. 2) shows the values of the Induction and the square root of the observed Tractive Force, the theoretical values being represented by the straight line whose inclination is determined by the factor

$$
\sqrt{\bar{A}} \overline{i \pi}
$$




\begin{tabular}{|c|c|c|c|}
\hline $\begin{array}{l}\text { Intensity of } \\
\text { Magnetization. } \\
\text { I. C G.S. }\end{array}$ & $\begin{array}{l}\text { Induetion. } \\
\text { B. C.G.S. }\end{array}$ & $\begin{array}{c}\text { Square root of } \\
\text { number of grams. } \\
\text { supported. }\end{array}$ & $\begin{array}{l}\text { Calculated value } \\
\text { of square root of } \\
\text { Tractive Force. }\end{array}$ \\
\hline 493 & 6198 & $52 \cdot 10$ & $52 \cdot 04$ \\
\hline 551 & 6929 & 5905 & $58 \cdot 40$ \\
\hline 646 & 8122 & $68 \cdot 61$ & $68 \cdot 65$ \\
\hline 853 & 10726 & 90.86 & 90.59 \\
\hline 996 & 12517 & 105.00 & $105 \cdot 60$ \\
\hline 1163 & 14635 & $122 \cdot 30$ & 123.50 \\
\hline $129 !$ & 16261 & 136.80 & $137 \cdot 30$ \\
\hline 1346 & 16975 & 14260 & $143 \cdot 20$ \\
\hline 1400 & 17690 & $148 \cdot 7$ & $149 \cdot 30$ \\
\hline 1463 & 18545 & 1558 & $156: 50$ \\
\hline 1550 & 197.29 & 1.64 .2 & $166 \cdot 60$ \\
\hline 1585 & 20234 & $168^{\circ} 4$ & $170 \cdot 80$ \\
\hline
\end{tabular}

Fig. 2.-Soft iron Ellipsoid of Revolution cut in equatorial plane and interface polished. Area of surface of contact $=1.767$ square centim.

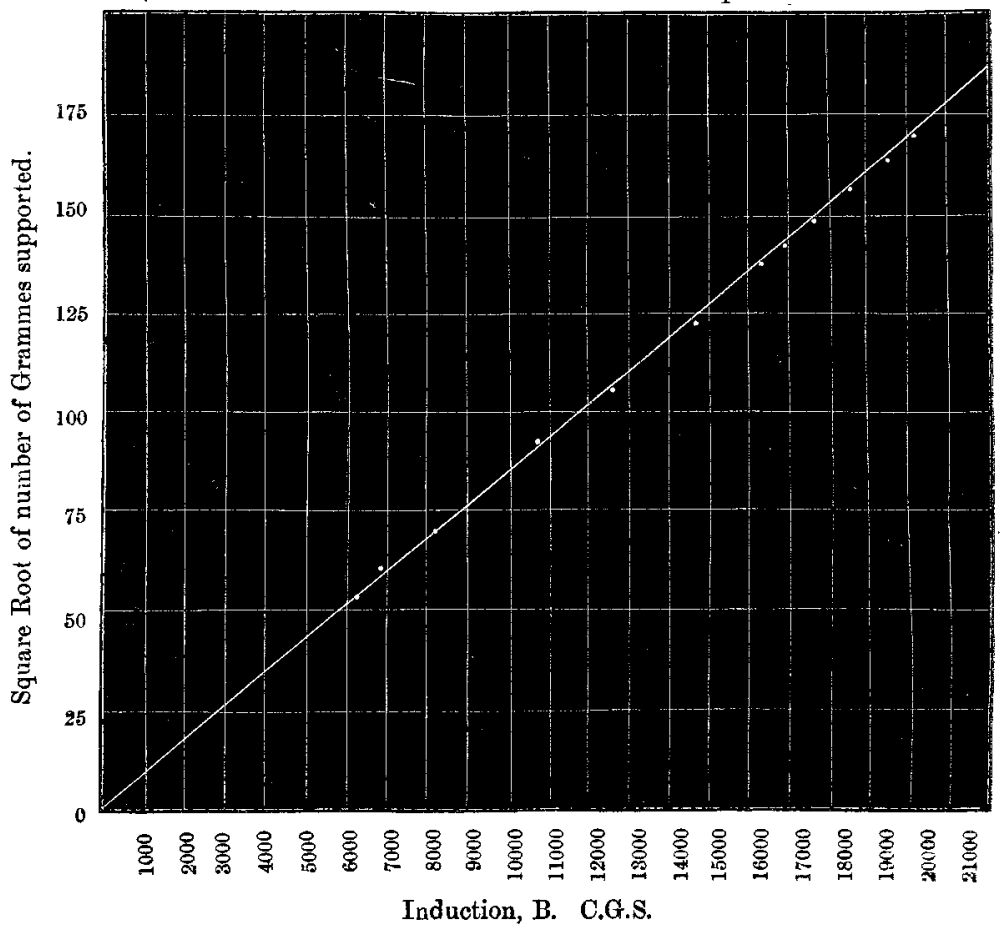




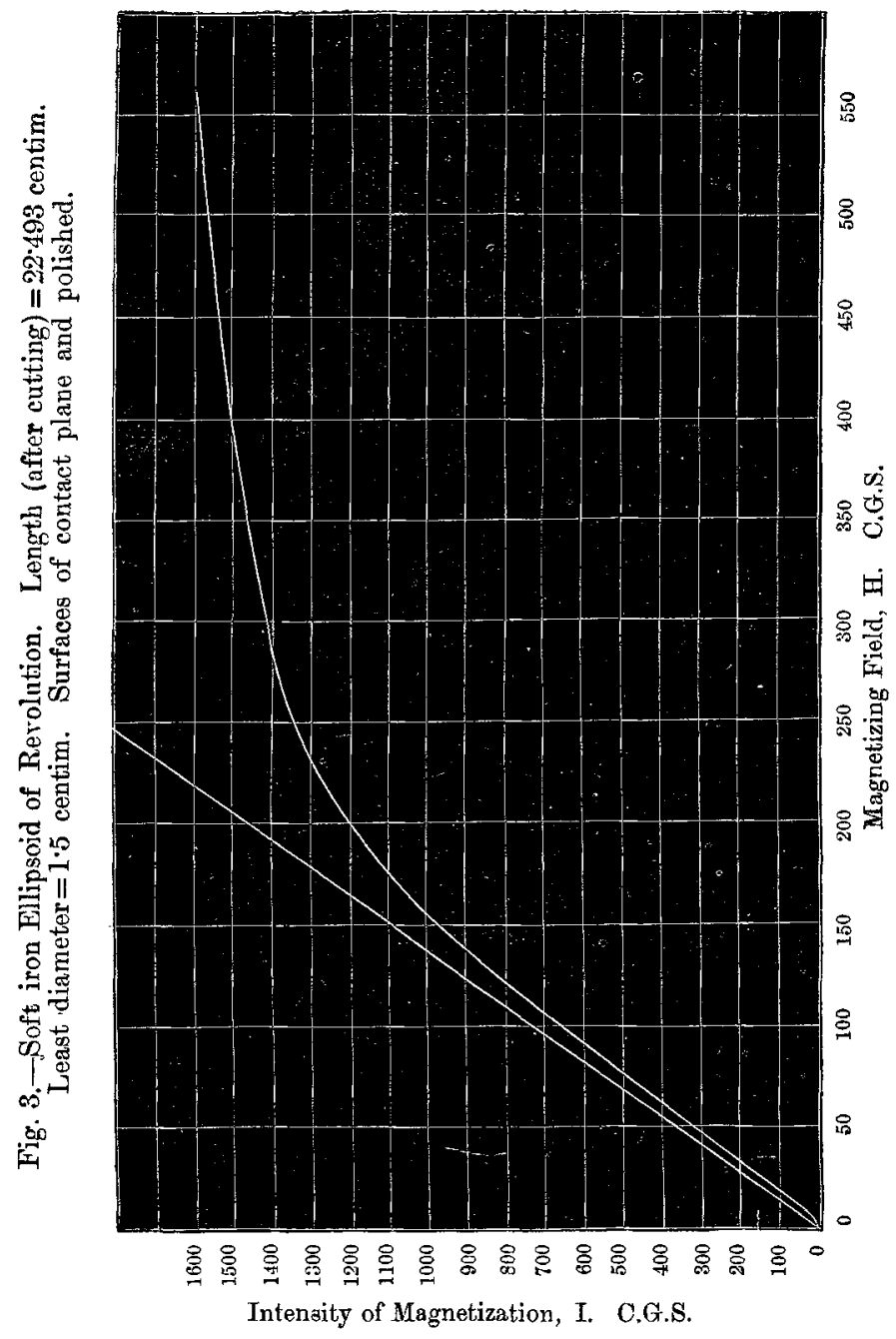


Fig. 3 represents the magnetization-curve and the demagnetizing force of the ellipsoid.

Each observation was repeated several times, and the mean value taken as the true value. The weights, however, never differed by more than 1 or 2 per cent. for the same magnetizing current.

It appears therefore that the present method of measurement has great advantages over the ballistic method used by Bosanquet and Threlfall, for Bosanquet obtained sometimes for the same induction weights differing by nearly 20 per cent.

The apparatus as above described (or any apparatus of the S. P. Thompson's "permeameter" * type) may therefore be used for the accurate measurement of magnetic induction in uniformly magnetized bars, the essential conditions being that the contact surfaces are plane, that the upper bar can be finely adjusted in position and very rigidly fixed, and that the contact surfaces are as nearly. as possible flush with the ends of the magnetizing-coils, space being left for the small guiding-ring on one of the bars. 'The lower bar must also be guided, and for this it is sufficient that its lower end pass freely through a ring properly adjusted in position.

A few experiments were made with the half-cores separated by very thin sheets of silver. Two sheets were used, of thicknesses 1.5 and 8 hundredths millim. respectively, and it was found that the introduction of a sheet always caused a diminution of both magnetization and tractive force, greater with the thicker sheet. No increase similar to that found by Wassmuth $\dagger$ at low inductions was observed.

In conclusion, I wish to express my obligations to the late Prof. Kundt and Drs. du Bois and Rubens for the interest they took in my work, and the help they gave me in various ways.

Berlin Phys. Inst. d. Univ., Jan. 1895.

* Journ. Soc. Arts, Sept. 12, 1890.

† L. c. p. 336 